\title{
Stimulus uncertainty, response uncertainty, and stimulus-response compatibility as determinants of schizophrenic reaction time performance
}

\author{
D. R. HEMSLEY \\ Institute of Psychiatry, De Crespigny Park, Denmark Hill, London, England SE5 8AF
}

\begin{abstract}
The results of studies investigating schizophrenic reaction time performance as a function of task complexity are contradictory. A distinction must be made between the effects of varying stimulus uncertainty and response uncertainty. It is also necessary to consider the stimulus-response compatibility of the task: With high compatibility, the effects of response uncertainty are minimized. A review of studies indicates that the slope function relating reaction time to task complexity is steeper in schizophrenics than in control subjects only where response uncertainty is varied and the task has low stimulus-response compatibility. The evidence is consistent with theories emphasizing a deficit at the stage of response selection in schizophrenia.
\end{abstract}

The generalized slowness of schizophrenics, over a wide range of tasks, is well established (e.g., King, 1954). There are, however, contradictory findings concerning the extent of the schizophrenic deficit as a function of varying degrees of task complexity. The aim of the present article is to clarify these results.

The degree of schizophrenic deficit as a function of task complexity is relevant to Yates' (1966) suggestion that schizophrenics show a slowness in processing information, a formulation based on Broadbent's (1958) concept of a limited-capacity decision channel. This, in turn, was influenced by the results of investigators such as Hick (1952), who demonstrated a linear relationship between reaction time and the logarithm of the number of equiprobable stimulus alternatives; the slope of this function was regarded as an inverse measure of the capacity of the decision channel. In Hick's (1952) study, stimulus and response uncertainty varied simultaneously; subsequent research has attempted to separate these effects. The results suggest that, while both influence reaction time, the effects of response uncertainty are greater (e.g., Garner, 1962). It will be argued that the distinction between stimulus and response uncertainty is relevant to the findings on the choice reaction time performance of schizophrenics.

The model of choice reaction time suggested by communication theory has required considerable modification; it has been argued that there is a log/linear relationship between task complexity and reaction time, this relationship holding irrespective of whether the increase in complexity refers to stimuli, responses, or memory load (Briggs \& Johnsen, 1973; Briggs \& Swanson, 1970). While the usefulness of such models in understanding response latency distributions has been seriously questioned (Laming, 1968), a recent review suggests that the quantitative expressions of the theory

This paper is sponsored by Arthur L. Benton, who takes full editorial responsibility. have continued to provide an adequate description of the average reaction times in a variety of situations (Audley, 1973). It has remained popular with investigators of schizophrenics' choice reaction time performance.

One of the earliest problems of the communication theory model was stimulus-response compatibility, the degree of naturalness or obviousness of the response appropriate to a particular signal. While it is difficult to avoid circularity in the definition of compatibility, Broadbent (1971) has suggested that, given an array of possible stimuli and possible responses, the degree of compatibility is represented by the ability of unpracticed subjects to guess the response which is correct for a particular stimulus. The effect of prolonged practice on a given task is similar to that of high stimulus-response compatibility; both reduce the slope relating reaction time to the logarithm of the number of stimulus-response alternatives (Welford, 1968). For example, Crossman (1956) used a row of response keys that closely corresponded spatially to the row of signal lights; increasing the number of stimulus-response alternatives resulted in only a small increase in reaction time. The idea of the slope as an inverse measure of channel capacity is therefore difficult to maintain. Wickens (1974) has recently suggested that, with high stimulus-response compatibility or prolonged practice, the response selection stage is bypassed by a direct stimulus-response association or link. Similarly, Welford (1968) has indicated that in such circumstances the association between each stimulus and its appropriate response becomes "wired in." The effect of varying the number of stimulus-response alternatives may then be solely that due to varying stimulus uncertainty, which is, as was indicated above, less than that resulting from increasing response uncertainty.

In Table 1, the studies of schizophrenic choice reaction time performance are summarized as a function of stimulus uncertainty, response uncertainty, and stimulus-response compatibility. The notation employed 
Table 1

\begin{tabular}{|c|c|c|c|c|c|}
\hline Study & Control Group & $\begin{array}{l}\text { S and } R \text { Uncertainty } \\
\text { Variations } \\
\end{array}$ & Type of Task & $\begin{array}{l}\text { S-R } \\
\text { Compat- } \\
\text { ibility }\end{array}$ & Results \\
\hline King (1954) & Normals & $S_{0} R_{0}, S_{1} R_{1}$ & Discrete & Low & $\begin{array}{l}\text { Schizophrenics more affected } \\
\text { by increasing task complexity }\end{array}$ \\
\hline Venables (1958) & Normals & $S_{0} R_{0} \rightarrow S_{3} R_{3}^{*}$ & Discrete & High & No difference in slope function \\
\hline $\begin{array}{l}\text { Benton et al. } \\
\text { (1959) }\end{array}$ & Normals & $S_{0} R_{0}, S_{1} R_{1}$ & Discrete & High & No difference in slope function \\
\hline Venables (1965) & Normals & $\mathrm{S}_{5.7} \mathrm{R}_{1} \rightarrow \mathrm{S}_{5.7} \mathrm{R}_{4.7} \dagger$ & Continuous & Low & $\begin{array}{l}\text { Schizophrenics more affected } \\
\text { by increasing response uncer- } \\
\text { tainty }\end{array}$ \\
\hline Karras (1967) & Mixed psychiatric & $S_{0} R_{0}, S_{1} R_{1}$ & Discrete & High & No difference in slope function \\
\hline $\begin{array}{l}\text { Court and } \\
\text { Garwoli (1968) }\end{array}$ & Normals & $\begin{array}{l}S_{0} R_{0}, S_{1} R_{1}, S_{2} R_{2} \\
S_{3} R_{3}\end{array}$ & Discrete & High & No difference in slope function \\
\hline Slade (1971) & $\begin{array}{l}\text { Mixed nonpsychotic } \\
\text { psychiatric patients }\end{array}$ & $\begin{array}{l}S_{1} R_{1}, S_{2} R_{2}, S_{3} R_{3} \\
S_{4} R_{4}\end{array}$ & Continuous & Low & $\begin{array}{l}\text { Schizophrenics more affected } \\
\text { by increasing task complexity }\end{array}$ \\
\hline Karras (1973) & $\begin{array}{l}\text { Depressives and } \\
\text { neurotics }\end{array}$ & $\begin{array}{l}S_{1} R_{0}, S_{1} R_{1} \\
S_{1} R_{0}, S_{1} R_{1}\end{array}$ & $\begin{array}{l}\text { Discrete } \\
\text { Discrete }\end{array}$ & $\begin{array}{l}\text { High } \\
\text { Low }\end{array}$ & $\begin{array}{l}\text { No group difference on slope } \\
\text { Depressives and schizophrenics } \\
\text { more affected by increasing } \\
\text { task complexity than neurotics }\end{array}$ \\
\hline Marshall (1973) & $\begin{array}{l}\text { Neurotics and } \\
\text { prisoners }\end{array}$ & 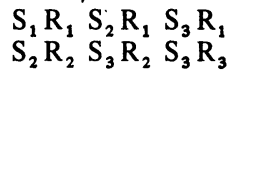 & Continuous & Low & $\begin{array}{l}\text { Schizophrenics more affected } \\
\text { by increases in both stimulus } \\
\text { and response uncertainty. } \\
\text { Response uncertainty effects } \\
\text { greatest }\end{array}$ \\
\hline Hemsley (1976) & Depressives & 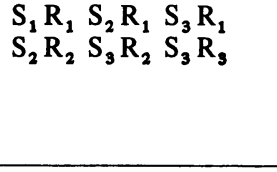 & Continuous & Low & $\begin{array}{l}\text { Schizophrenics more affected } \\
\text { by increasing response uncer- } \\
\text { tainty. No difference in the } \\
\text { effects of increasing stimulus } \\
\text { uncertainty }\end{array}$ \\
\hline
\end{tabular}

*Eight conditions

tSeven conditions

follows that of Marshall (1973). Thus $S_{\log _{2} n}$ represents the degree of stimulus uncertainty, $n$ being the number of equiprobable stimulus alternatives; $R_{\log _{2} \mathrm{~m}}$ represents the degree of response uncertainty, $m$ being the number of equiprobable response alternatives. In all the studies, the schizophrenics were slower overall than the control groups. This paper is concerned only with the degree to which the schizophrenic deficit varies as a function of task complexity, that is, the extent to which the slopes relating reaction time to stimulus and response uncertainty differ across groups.

The results can be summarized as follows: The degree of schizophrenic deficit increases mainly as a function of increasing response uncertainty; this is, however, apparent only on tasks with low stimulus-response compatibility. An illustration of a highly compatible task is that of Venables (1958), requiring subjects to name the number on the light which was lit; stimulus and response uncertainty varied together from $S_{0} R_{0}$ to $S_{3} R_{3}$. No slope difference was found. An incompatible task is typified by the choice reaction time card-sorting experiment of Slade (1971), which varied stimulus and response uncertainty from $S_{1} R_{1}$ to $S_{4} R_{4}$; here the relationship between stimulus and sorting position was of low compatibility and a significant slope difference was found. The exception to the above generalization is the study of Karras (1973), who failed to find a significant slope difference between schizophrenics and depressives even on his incompatible task, although the results were in the predicted direction. Both groups differed significantly from the neurotic controls. These findings may be related to the limited range of response uncertainty variation in his task, from $S_{1} R_{0}$ to $S_{1} R_{1}$. It must be noted, however, that the low-compatibility tasks, on which the schizophrenic deficit has appeared, have mostly been continuous rather than discrete reaction time tasks; the majority of the latter have employed compatible stimulus-response relationships. In view of the equivocal findings of Karras (1973), experiments should be carried out with discrete reaction time tasks of low stimulus-response compatibility to test the present suggestions.

If Wickens' (1974) model is adopted and the response selection mechanism considered bypassed on highly compatible tasks, and if we further suggest that a deficit at the level of response selection is of primary importance in schizophrenic performance, the apparently contradictory findings are resolved. This is also consistent with the extensive data presented by Broen (1968) indicating that the schizophrenic's cognitive deficit is primarily a difficulty in response selection rather than in sampling input. Of interest for future research is the 
extent to which schizophrenics are able to bypass the response selection mechanism as a result of prolonged practice on a task of previously low stimulus-response compatibility.

\section{REFERENCES}

Audley, R. J. Some observations on theories of choice reaction time: A review. In S. Kornblum (Ed.), Attention and performance IV. New York: Academic Press, 1973.

Benton, A. L., Jentsch, R. C., \& Wahler, H. J. Simple and choice reaction times in schizophrenia. Archives of Neurology and Psychiatry, 1959, 81, 373-376.

Briggs, G. E., \& Johnsen, A. M. On the nature of central processing in choice reactions. Memory \& Cognition, 1973, 1, 91-100.

Briggs, G. E., \& Swanson, J. M. Encoding, decoding, and central functions in human information processing. Journal of Experimental Psychology, 1970, 86, 296-308.

Broadbent, D. E. Perception and communication. London: Pergamon Press, 1958.

Broadbent, D. E. Decision and stress. London and New York: Academic Press, 1971.

Broen, W. E. Schizophrenia: Research and theory. New York: Academic Press, 1968.

CourT, J. H., \& GARWoli, E. Schizophrenic performance on a reaction time task with increasing levels of complexity. British Journal of Social and Clinical Psychology, 1968, 7 , 216-223.

Crossman, E. R. F. W. The information capacity of the human operator in symbolic and non-symbolic control processes. In J. Draper (Ed.), The application of information theory to human operator problems (Report No. 2/56). London: Ministry of Supply, 1956.

GARNER, W. R. Uncertainty and structure as psychological concepts. New York: Wiley, 1962.
Hemsley, D. R. Attention and information processing in schizophrenia. British Journal of Social and Clinical Psychology, 1976, 15, 199-209.

Hick, W. E. On the rate of gain of information. Quarterly Journal of Experimental Psychology, 1952, 4, 11-26.

KarRAs, A. The effect of stimulus-response complexity on the reaction time of schizophrenics. Psychonomic Science, $1967,7,75-76$.

KARRAS, A. Effects of competing and complex responses on the reaction time of acute psychiatric groups. Journal of Abnormal Psychology, 1973, 82, 134-138.

KIng, H. A. Psychomotor aspects of mental illness. Cambridge: Harvard University, 1954.

LAMING, D. R. J. Information theory of choice reaction times. New York: Academic Press, 1968.

Marshall, W. L. Cognitive functioning in schizophrenia: I. Stimulus analyzing and response selection processes. British Journal of Psychiatry, 1973, 123, 413-423.

SLADE; P. D. Rate of information processing in a schizophrenic and a control group: The effect of increasing task complexity. British Journal of Social and Clinical Psychology, 1971, 10, 152-159.

VenABles, P. H. Stimulus complexity as a determinant of the reaction time of schizophrenics. Canadian Journal of Psychology, 1958, 12, 187-190.

Venables, P. H. Slowness in schizophrenia. In A. T. Welford \& J. E. Birren (Eds.), Behaviour, ageing and the nervous system. Springfield, Ill: Charles C. Thomas, 1965.

WELFord, A. T. Fundamentals of skill. London: Methuen, 1968.

Wickens, C. D. Temporal limits of human information processing: A developmental study. Psychological Bulletin, $1974,81,739-755$.

YATES, A. J. Data processing levels and thought disorder in schizophrenia. Australian Joumal of Psychology, 1966, 18, 103-117.

(Received for publication July 30, 1976.) 